\title{
Las exenciones fiscales y el problema de la vivienda
}

I. Hay un hecho innegable, cual es la extraordinaria escasez de viviendas, sobre todo en las ciudades españolas, principalmente en las que las destrucciones de la guerra fueron mayores. La reconstrucción se inicia lentamente y concurriendo otras causas, cual el aumento de servicios burocráticos, el creciente éxodo del campo a la ciudad, y, por otra parte, la elevación del nivel medio de vida que se traduce en el anhelo de una vivienda cómoda e higiénica, es lo cierto que en muchas de estas ciudades es verdaderamente angustioso este difícil problema que tantos males y tantas perturbaciones económicas y familiares motiva; junto a esta realidad angustiosa hay que señalar un hecho cierto: es la constante preocupación del Gobierno en su decisión firmísima de resolver tan crítica situación movilizando para ello créditos cuantiosos, estimulando la acción de Organismos públicos y sindicales para que se construyan viviendas en cantidad necesaria que permita asegurar un hogar digno a todos los españoles.

II. De todas las iniciativas hasta el presente desarrolladas y patrocinadas por el Gobierno, cabe mencionar la recogida en la Ley de 25 de noviembre de 1944, desarrollada después en Reglamento y en otras disposiciones posteriores, en las que tanta ilusión puso nuestro Gobierno, aun cuando la realidad, lo que tememos, las defraude en gran parte. Ciertamente que son importantes las bonificaciones tributarias que el Estado concede a estas viviendas, pero la verdad es que la limitación de 
alquileres establecida no responde al precio de las cosas en el momento actual y, sobre todo, no se ajusta a la cotización real de las obras de las ciudades de segunda y tercera categoría, para las que se fijan unos alquileres muy limitados, precisamente en momentos en que es tan caro construir en ellas como en las populosas ciudades. Esta realidad no puede desconocerse $y$, por tanto, si se cercena la renta en este grupo importantísimo de pequeñas poblaciones y no se logra eficacia ninguna a las disposiciones complementarias que promulgó el Gobierno, por ejemplo, a las que concedía preferencia para suministro de hierro y cemento, prácticamente resultarán ineficaces estas exenciones fiscales, por no estar compensadas con.la renta excesivamente baja que se impone para las viviendas que se construyan en ese gran número de pequeñas ciudades, que es tan angustioso y tan acucioso el problema de los que no tienen casa.

III. Con exacto conocimiento del problema el Gobierno ha pensado que las construcciones de carácter oficial no bastarán para resolverlo. Ha querido estimular la iniciativa privada, ha querido alentar a los particulares para que se decidan a la construcción de viviendas, y para ello, en el artículo $6 .^{\circ}$ de la Ley de 25 de noviembre de 1944 , concede la reducción en un 90 por 100 , y durante el plazo de veinte años, de las contribuciones siguientes:

a) Contribución urbana.

b) Impuesto de Derechos reales, Timbre del Estado y Municipales :

1. En la transmisión de terrenos adquiridos a partir de la promulgación de la presente Ley para construir sobre ellos los edificios beneficiados.

2. En todas las operaciones de constitución y cancelación de préstamos hipotecarios, cuyo importe en su totalidad se conceda o invierta en la construcción de los edificios acogidos a dicha Ley.

3. Derechos Reales y Timbre que graven la primera transmisión a título oneroso, de las fincas acogidas a esta Ley y totalmente construídas. 
4. Impuesto de Derechos Reales y Timbre en los contratos de ejecución de obras referente a estas fincas.

Cuantiosa es la renuncia que hace el Tesoro con estas bonificaciones fiscales, pero estimamos ineficaces estas medidas para que la iniciativa privada se lance a la construcción de viviendas.

IV. Los particulares construyen hoy pocas viviendas, debido, principalmente, a una serie de concausas que en un intento de síntesis pudiéramos agrupar así:

a) De tipo fiscal, y son el rigor contributivo a que está sometida la propiedad urbana, tanto por el Estado como por los Ayuntamientos.

b) De tipo juridico, representada por los privilegios y prerrogativas concedidos a los inquilinos, que implican un cercenamiento exagerado para la propiedad, convertida de hecho en un usufructo con antipáticas limitaciones.

c) De tipo técnico-económico, entre las que cabe citar el enorme encarecimiento de solares, la ilimitada e inestable elevación de precios de materiales de construcción y la irregularidad a que en la práctica está sometida la adquisición de los mismos, ya que se acentúa el acaparamiento oficial de estos materiales con destino a servicios públicos ciertamente privilegiados.

Desde que por la Ley de Reforma Tributaria, obra del insigne Larraz, se concedió a los inquilinos, cualquiera que sean los pactos o contratos que le liguen con el dueño de su vivienda, a limitar su alquiler por todos los conceptos a la cifra declarada por éste, entendiéndose al efecto novado el contrato, desapareció, por lo menos en los pueblos y las ciudades importantes, la gran ocultación que habia en las bases de urbana. Son ya hoy legión los propietarios que tienen hoy declaradas al céntimo las rentas que percibe, que tributan sobre ellas a tipos bastante elevados, sobre todo si se conjugan con otras prestaciones municipales, timbres, Fiscalía de la Vivienda, etcétera, etc.

V. A nuestro entender, se ha acentuado mucho por el poder público las limitaciones impuestas al propietario. Cierto que 
esta propiedad tiene una función social destacadísima, sobre todo en momentos de crisis como el presente, y nos parece admirable cuanto se haga en este sentido, pero es curioso observar que se desatienden o se olvidan aspectos interesantísimos de esta función social para, en cambio, extremar los rigores en otros casos; por ejemplo, el propietario que tiene ociosa la casa, que no la habita o que sencillamente simula habitarla merece todos los respetos, y no obstante haber otros semejantes que no tienen hogar, que no encuentran la casa donde situar a su familia, permanecen ociosos totalmente desaprovechados; en cambio, el que alquila está sometido a una serie de cargas, de limitaciones que desintegran las funciones dominicales para arrebatárselas al propietario y convertirlo en un mero usufructuario cuyas facultades de goce también quedan muy mermadas. Es lamentable que no se vigile el que los inquilinos cumplan un mínimum de obligaciones en cuanto a la buena conservación de la vivienda e incluso a las prácticas más elementales en cuanto al aseo y adecentamiento de su propia vivienda. El propietario quiere sentirse propietario, no en el concepto quiritario ya derogado en todas las legislaciones, sencillamente propietario de su casa sin estar a merced de tanta fiscalización, de tanta medida restrictiva, que en muchos casos llega hasta a privarle de la posibilidad de elegir el inquilino. Téngase presente que con el tope fijado a los alquileres con la obligada adaptación a la renta declarada, desaparecerán muchas ambiciones que fueron en infinitos casos estímulo de torpes actuaciones por parte de algunos propietarios.

VI. A nuestro modesto criterio, el estímulo para la construcción de viviendas exige un robustecimiento de la autoridad del propietario, y junto a ello facilitarle el desdoblamiento de sus viviendas. Sería muy interesante estimular estas obras, tanto en sentido vertical como horizontal, ya que además razones económicas muy poderosas así lo aconsejan. Son muchísimas las casas que tienen sólidos cimientos que, por encontrarse en buen estado de conservación, permitirían que se les adicionase una planta o dos más. La expansión en este sentido aumentaría un número muy considerable de viviendas con rentabilidad 
estimable y ello moveria a muchos propietarios a iniciar estas reformas. Técnicamente se pueden ejecutar con un coste bastante reducido; se construye sobre solar yá ocupado, con paredes maestras bien cimentadas, en muchos casos con aprovechamiento de la propia cubierta cuidadosamente desmontada, y como, por otra parte, el espesor de los muros de estas plantas añadidas, según la técnica moderna, puede ser bastante reducido, sin temor alguno el propietario se lanzaria a estas obras en la seguridad de que obtendría un interés muy remunerador a las inversiones que efectuase.

De esta forma se pondría en planta un gran número de viviendas con ventajas también para la economía nacional y para la propia ciudad, ya que sin ocupación de nuevos terrenos se facilitarían viviendas, evitando el excesivo desplazamiento que, como consecuencia de los planes de ensanche, se producen en nuestras ciudades, perturbando con ello la buena marcha de los servicios urbanísticos (1). Pero esto tiene hoy el inconveniente del respeto que ha de guardarse a los habitantes de los últimos pisos, que en parte habrán de ser desmontados para el mejor entronque y enlace de la nueva edificación, y en este sentido el legislador debiera reducir los privilegios de esos inquilinos para facilitar que se ejecutasen estos desdoblamientos de pisos y pudieran habilitarse nuevas viviendas, siquiera fuera

(1) Esto permitiria: a) el aprovechamiento de las instalaciones domésticas con el considerable ahorro que supone el montaje de las mismas, sustituida por los pequeños gastos que supondria la ampliación de las mismas, v. gr., en las calefacciones, ascensores, vertido de basuras, recogida de aguas, etc.; b) aprovechamiento integral de las instalaciones y servicios urbanos ya existentes, v. gr., alcantarillado, servicio de aguas, alumbrado, etc., con la consiguiente comodidad y bienestar para los vecinos y la economia extraordinaria que supone para la Hacienda Municipal no tener que hacer desembolso alguno para dotar de los mismos las nuevas zonas; c) evita la ocupación de nuevos solares; d) economiza una gran masa de materiales de construcciones al no tener que efectuar cimentaciones, con el consiguiente ahorro de los cuantiosos jornales y elementos de trabajo que en ellas se invertiría ; $e$ ) evita la disgregación de la población, que de otra forma se alejaría de los centros vitales, la zona de comercio, los colegios, escuelas, Iglesias y Organismos oficiales, y $f$ ) economiza los cuantiosos gastos que de otra forma los Municipios tendrán que recobrar para organizar los servicios de vialidad de los transportes y ornato de los nuevos núcleos urbanos. 
reservándole el derecho a volver a ocuparlas en las condiciones anteriores tan pronto como la obra quedase ejecutada.

Hay que consagrar el Derecho a favor del propietario para realizar estas obras de ampliación de sus edificios, y hará bien el legislador en sancionar al propietario que, so pretexto de realizar estas obras, lanzase a alguno de sus inquilinos y éstas quedasen sin ejecución. Hoy tienen las Cortes españolas pendiente de ultimar la Ley de arrendamientos urbanos; deseamos vivamente que, al elaborar Ley tan importante, tengan en cuenta las observaciones precedentes inspiradas en el deseo de cooperar, siquiera sea sin autoridad alguna, a resolver el grave problema que plantea la gran escasez de viviendas en tantas ciudades y pueblos de España.

Cirilo Martín Retortillo.

Abogado del Estado 